\title{
Copyright Law and Artificial Intelligence
}

\section{Gerald Spindler}

Published online: 15 October 2019

(C) Max Planck Institute for Innovation and Competition, Munich 2019

Artificial intelligence (AI) has become one of the hottest topics in more or less all legal areas, be it liability, criminal law, legal tech, or even agricultural law. Hence, it is no surprise that AI also raises issues in copyright law, mainly concerning two different questions. The first refers to the creation of works with the help of AI, the second deals with copyright protection of AI itself.

Regarding AI as a tool to create works, we have to be aware that even though AI seems to be equivalent to the human mind (as the notion of "intelligence" suggests), in reality AI is still far from being really "intelligent". Much depends on the definition of "intelligence": if "intelligent" is understood as finding new ways not already known, AI may be called "intelligent" as it can detect new relationships in big data heaps, which was not possible earlier. Furthermore, AI can learn from previous errors and mistakes and improve the patterns of its program. Thus, some argue that the author no longer has sufficient control over how the work is being created and under which conditions. However, AI in its present forms cannot determine the preferences or goals to be achieved; it is still up to the human being implementing and using AI to define the areas and goals for it. In other words, AI may improve ways to achieve a goal but cannot change it. Hence, suggestions to qualify AI (or robots) as a new form of legal person (a so-called "ePerson") disregard these facts. Moreover, such suggestions do not answer the crucial questions of how AI could be held liable or could raise money to handle claims against it (or robots). Ultimately, the real question regarding all legal areas concerns to a greater extent the issue of whether the actions of AI can be attributed to the human being using it.

In copyright law, AI raises the question whether works created by it can still be regarded as a personal intellectual creation, which is crucial for acknowledging

G. Spindler $(\bowtie)$

Professor Dr.; Department of Corporate Law, Civil Law - Internet Law, Copyright and Telecommuncation Law, Faculty of Law, University of Goettingen, Goettingen, Germany e-mail: info@gerald-spindler.de 
copyright protection for a work. As the behaviour of AI is more or less unpredictable, the traditional "deterministic" approach concerning the use of digital tools can no longer be applied. Before the development of AI, the use of software could simply be attributed to the author, as the outcome is in principle foreseeable. The situation changes if the author uses an AI and can only set the main preferences and goals to be achieved. The situation is to a certain extent comparable to works of art created using software which randomises the use of colours, etc. The outcome of using AI, however, cannot be predicted, so some authors argue that the main part of the "creative process" has been provided by AI - rather than by the author - so that ultimately the outcome cannot be considered as determined by a human being and thus would not be acknowledged as a copyrightable work. On the other hand, such a perspective seems to overstate the role of creativity and the range/capabilities of AI. AI is not "intelligent" in a legal sense; in other words, it cannot be compared to a human will. And as AI cannot set its own goals and preferences, it is still the author who makes use of AI and who defines the framework within which the specific work will be created. Thus, there are still good arguments to attribute the work created by AI to the individual making use of it. If, for instance, an artist decides to train an AI based on the paintings of Rembrandt and then the AI construes a "new Rembrandt", it depends to what extent the artist influenced the AI. If the artist used only certain paintings (and not all of them), then there is a strong influence on the creation of the final "AI painting". In this case the work should be attributed to the artist. If, however, an artist chooses to train the AI based on all paintings, including those of other artists, then the setting of goals and the framework is significantly less meaningful. If an artist does not even know how the AI has been trained (as, for instance, concerning the completion of Mahler's unfinished 10th symphony) it is hard to speak of the creativity of the artist.

The other relevant aspect from a copyright law perspective concerns the protection of AI itself. Under the current legal framework, it is not AI as a concept or as an algorithm that is protected, rather it is AI as a code on the grounds of the EU Software Directive. Moreover, data which is used for training an AI is not protected as such. If the AI is based on a database, then the structure of this database is protected according to the EU Database Directive. Also, data produced by AI is currently not protected under copyright law. However, new data generated by an AI system can be qualified as a trade secret according to the new EU Directive on the protection of undisclosed know-how and business information (trade secrets). However, this protection is clearly weaker than that under copyright law as trade secrets are not real property rights.

Looking to the future, the situation may change if AI ultimately becomes able to turn around the goals and preferences set by its owner. Even if that still seems far away and something from science fiction, in that case we will need to consider the introduction of new forms of legal persons because the activities of AI can no longer be attributed to the "author". The "governance" of such a new person, including control of it, has then to be carved out more precisely. Moreover, regarding the protection of data used for training AI as well as data generated by it, it is debatable whether protection as a trade secret is sufficient. On the other hand, new developments in information technology make it likely that data and its use can be 
traced, so that the boundaries and limits of data use may be controlled through technological means. Thus, the introduction of legal property rights may not be necessary as technological tools could be quite effective. In addition, business-tobusiness platforms have developed standard contractual terms and conditions in order to share data whilst protecting it against unfair use. Thus, in the end the evolution of AI should be closely monitored, and furthermore how data is traded and protected by contractual terms. For the time being there seems to be no need for legislative action concerning the extension or modification of copyright protection.

Publisher's Note Springer Nature remains neutral with regard to jurisdictional claims in published maps and institutional affiliations. 